\title{
APPLICATIONS OF CERTAIN DIFFERENTIAL INEQUALITIES TO THE UNIVALENCE OF AN INTEGRAL OPERATOR
}

\author{
GEORGIA IRINA OROS
}

Abstract. In [1] we have introduced the integral operator denoted by $I\left(f_{1}, f_{2}, \ldots, f_{m}\right)$ given in Definition 2. Also, certain sufficient conditions of univalence were given for this operator. In this paper we take a different approach for proving the univalence of this operator.

Mathematics subject classification (2000): 30C45, 30A20, 34A40.

Keywords and phrases: Analytic function, univalent function, differential operator, integral operator.

\section{REFERENCES}

[1] Georgia Irina Oros, A univalence preserving integral operator, Journal of Inequalities and Applications, Volume 2008, Article ID 263408, 9 pages, doi:10.1155/2008/263408.

[2] Georgia Irina Oros, On an univalent integral operator, Int. J. Open Problems Complex Anlaysis (IJOPCA), 1, 2 (2009), 19-28.

[3] St. Ruscheweyh, New criteria for univalent functions, Proc. Amer. Math. Soc., 49 (1975), 109-115. 